\title{
Drug Metabolism and Pharmacokinetics, the Blood-Brain Barrier, and Central Nervous System Drug Discovery
}

\author{
Mohammad S. Alavijeh, Mansoor Chishty, M. Zeeshan Qaiser, and Alan M. Palmer \\ Pharmidex, London W1S 1RR, United Kingdom
}

\begin{abstract}
Summary: The worldwide market for therapies for CNS disorders is worth more than $\$ 50$ billion and is set to grow substantially in the years ahead. This is because: 1) the incidence of many CNS disorders (e.g., Alzheimer's disease, stroke, and Parkinson's disease) increase exponentially after age 65 and 2) the number of people in the world over 65 is about to increase sharply because of a marked rise in fertility after World War II. However, CNS research and development are associated with significant challenges: it takes longer to get a CNS drug to market (12-16 years) compared with a non-CNS drug (10-12 years) and there is a higher attrition rate for CNS drug candi-
\end{abstract}

dates than for non-CNS drug candidates. This is attributable to a variety of factors, including the complexity of the brain, the liability of CNS drugs to cause CNS side effects, and the requirement of CNS drugs to cross the blood-brain barrier (BBB). This review focuses on BBB penetration, along with pharmacokinetics and drug metabolism, in the process of the discovery and development of safe and effective medicines for CNS disorders. Key Words: Blood-brain barrier, CNS drug discovery, DMPK, pharmacokinetics, pharmacodynamics, microdialysis, MDCK cells, in silico prediction of brain permeation, aging, brain disorders.

\section{INTRODUCTION}

The population of the world is getting older. During the first 50 years of this millennium, the worldwide population aged over 65 years is projected to increase from $6.9 \%$ of the total population to $15.9 \%$, which constitutes an extra billion elderly individuals. This is attributable to a combination of a progressive increase in life expectancy and elevated fertility in many countries during the two decades after World War II (i.e., the "Baby Boom" effect; Table 1). This growing number of older adults will increase the demands on both public health system and on medical and social services, particularly for chronic neurological disorders such as stroke, Alzheimer's disease, and Parkinson's disease. Such disorders affect older adults disproportionately and contribute to disability, diminish quality of life, and increased healthcare costs. Thus, stroke afflicts $30 \%$ of persons aged over 65 years (fatally in 10\%), and its incidence doubles during successive decades. Alzheimer's disease affects $10 \%$ of the population aged over 65 years and rises to $49 \%$ of those age 80 years or more. Parkinson's disease affects

Address correspondence and reprint requests to Alan M. Palmer, Pharmidex, 72 New Bond Street, London W1S 1RR, United Kingdom. E-mail: alan.palmer@pharmidex.com.
$1 \%$ of persons aged 60 or older and $2.6 \%$ of those over the age of 85 years. ${ }^{1}$

The widespread hope for a new era in the prevention and treatment of human disease that emerged with the sequencing of the human genome led to a marked upturn in the funding of drug discovery research. However, this brave new era has not yet arrived. Instead, the year 2000 marked the start of a slowdown in new drug and biologic submissions to regulatory agencies worldwide. ${ }^{2}$ The situation is made worse by the time taken to bring a new medicine to market (10-12 years to $12-16$ years for CNS drugs), the high cost of bringing a new medicine to market ( $\$ 0.8-1.7$ billion), and the imminent patent expiration for a large number of blockbuster drugs. ${ }^{3}$ Many thousands of compounds undergo the early stages of the process, but very few achieve drug status. Successful candidates have to fulfill the essential criteria of potency, selectivity, oral bioavailability (for orally administered drugs), therapeutic efficacy, along with an acceptable side effect profile. The probability of success also has a large dependence on the targeted therapeutic area, with CNS drugs having the lowest chance of success (FIG. 1). This is attributable to a variety of factors, including the complexity of the brain, the liability of CNS drugs to cause CNS side effects, and the requirement of CNS drugs to cross the blood-brain barrier (BBB). This review 
TABLE 1. Trends in World Population

\begin{tabular}{lrrr}
\hline Year & 1950 & 2000 & 2050 \\
\hline Total population (thousand persons) & $2,518,629$ & $6,070,581$ & $8,918,724$ \\
Population aged $>65$ (thousand persons) & 130,865 & 419,197 & 6.9 \\
Percentage of those aged $>65$ & 5.2 & 63.3 & $1,418,742$ \\
Male life expectancy at birth (years) & 45.2 & 67.6 & 72.0 \\
Female life expectancy at birth (years) & 47.9 & 2.7 & 76.7 \\
Total fertility rate & 5.0 & 2.0
\end{tabular}

Data derived from the 2002 revision of the United Nations World Population.

focuses on the role of BBB penetration in CNS drug discovery. Whether a molecule crosses the BBB is dependent upon its physicochemical properties, along with its pharmacokinetic profile in plasma, which in turn depends upon how the compound is absorbed, distributed, metabolized, and excreted. These factors will be considered in relation to drug discovery in general and CNS drug discovery in particular.

\section{THE SCIENCE OF DRUG DISCOVERY}

Drugs, chemical entities capable of influencing biological systems, have been used to treat human disease for thousands of years, mainly in the form of plant extracts. The first verifiable evidence of plants being used for medicinal purposes emerged in Sumeria 4000 years ago and was subsequently codified in meticulous detail, particularly in India and China. However, the science of pharmacology did not emerge until the 15th century with the work of Paracelsus (1493-1541), who mounted a vigorous attack on accepted paradigm of polypharmacy (e.g., one 15th century prescription contained 110 different ingredients) and insisted that drugs should undergo critical investigation. ${ }^{4}$

At the end of the 18th and the beginning of the 19th centuries, methods became available to isolate the active principles from crude drugs. The first pure active principle came from the poppy plant, an extract of which (opium) has probably been used for it psychoactive effects longer than any other agent-apart from ethanol. For centuries, opium appeared as a standard ingredient in

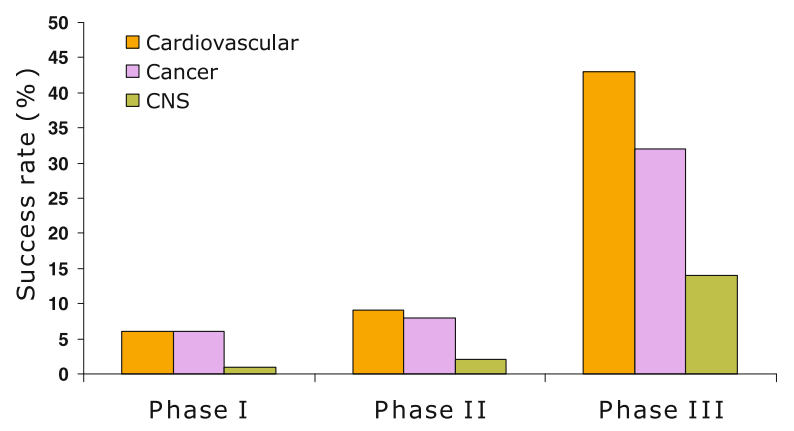

FIG. 1. Cumulative success rates of drugs to market by therapeutic area. Source: IMS International. all sorts of medicinal preparations and was extensively used recreationally, even though the dangers of addiction were well known. ${ }^{4,5}$

In 1803 Fredrich Sertuner, a 20-year-old German chemist, obtained the active substance from the poppy plant. He called it morphine, after Morpheus, the Greek god of dreams; morphine itself constituted about $10 \%$ of the total weight of the poppy! This stimulated the isolation of the active principles of other important medications (Table 2).

Plant extracts could only be administered orally. One of the advantages of using pure chemicals was that they could be dissolved in aqueous solutions and injected directly in to the bloodstream. This, together with the invention of the hypodermic syringe in 1853, meant that drugs, particularly analgesics, could be administered in a much more rapid and reproducible manner than was possible with orally administered plant extracts.

The main reason for this is that when a drug is administered by intravenous bolus, the amount of drug in the body immediately after injection is equal to the dose applied, $\mathrm{D}_{0}$. As elimination processes, such as metabolism and excretion, act on the compound, the amount of intact drug in the body declines in an exponential manner, according to the equation:

$$
\mathrm{D}=\mathrm{D}_{0} \mathrm{e}^{-k t}
$$

Where $\mathrm{D}$ is the amount of drug in the body at time $t, \mathrm{D}_{0}$ is the intravenous dose, which is the same as the amount of drug in the body, and $\mathrm{k}$ is the elimination rate constant.

A more frequently used expression to describe the rate at which a drug is removed from the body is the half-life. This is the time taken for the amount of drug in the body to decline to half of its value. The half-life and elimination constant are related by the equation:

$$
\mathrm{t}_{1 / 2}=0.693 / \mathrm{k}
$$

\section{ABSORPTION, DISTRIBUTION, METABOLISM, AND EXCRETION (ADME)}

\section{Absorption}

For a compound not given directly into the bloodstream by intravenous administration, the compounds 
TABLE 2. Plant-Derived Medications that Act on the Nervous System

\begin{tabular}{|c|c|c|c|}
\hline Drug & Structure & Isolated from & Utility \\
\hline Atrophine & & $\begin{array}{l}\text { Henbane } \\
\text { (Hyoscyamus niger) }\end{array}$ & $\begin{array}{l}\text { Ocular medication } \\
\text { (muscarinic } \\
\text { cholinergic receptor } \\
\text { antagonist) }\end{array}$ \\
\hline
\end{tabular}<smiles>O=CC(CO)c1ccccc1</smiles>

Digoxin

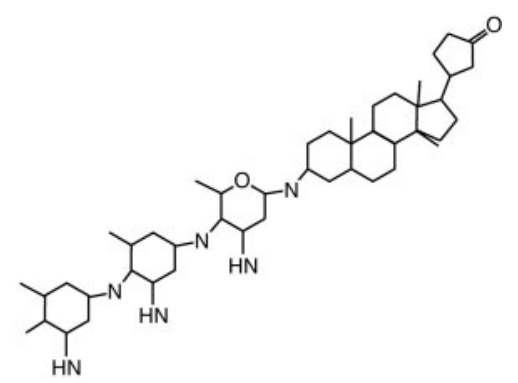

Ergotamine

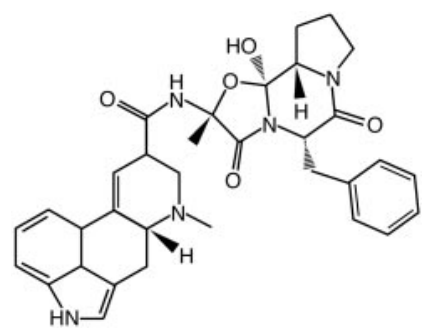

Physostigmine<smiles>CNC(=O)Oc1ccc2c(c1)[C@]1(C)CCN(C)[C@@H]1N2C</smiles>

Reserpine<smiles>COC(=O)[C@H]1C2C[C@@]3(C)c4[nH]c5cc(OC)ccc5c4CCC3C[C@@]2(C)C[C@H]1OC(=O)c1cc(OC)c(OC)c(OC)c1</smiles>

Theophylline<smiles>Cn1c(=O)c2nc[nH]c2n(C)c1=O</smiles>

Tubocurarine

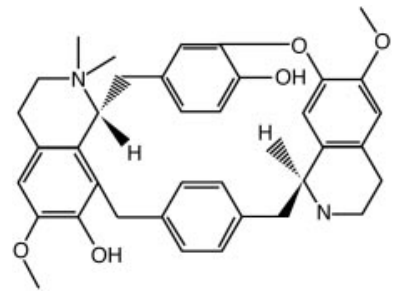

Foxglove

(Digitalis lanata)

Ergot

(Claviceps purpurea)

Calabar bean (Physostigma venenosum)

Indian snakeroot

(Rauwolfia serpentina)

Tea plant

(Camellia sinensis)

Curare vine (Chondrodendron tomentosum)
Heart medication; a cardiac glycoside (inhibition of $\mathrm{Na}^{+}$/ $\mathrm{K}^{+}$-ATPase)

Migraine medication (rasoconstriction via action at serotonin receptors)

Eye medication, particularly for glaucoma (inhibitor of acetylcholine-esterase)

Hypertension medication (depletion of momoamine neurotransmitters)

Bronchodialator (adenosine receptor antagonist)

Surgical muscle relaxant (nicotinic cholinergic receptor anatagonist) 
TABLE 3. Sites of Drug Administration and Absorption

\begin{tabular}{llc}
\hline Administration & Site of Absorption & $\begin{array}{c}\text { First Pass } \\
\text { Metabolism }\end{array}$ \\
\hline Mouth & Oral cavity & $\mathrm{X}$ \\
& Sublingual & $\mathrm{X}$ \\
Oral & Stomach & $\sqrt{ }$ \\
& Small intestine & $\sqrt{ }$ \\
Inhalation & Large intestine & $\sqrt{ }$ \\
Topical & Lungs & $\mathrm{X}$ \\
Intramuscular & Skin & $\mathrm{X}$ \\
Subcutaneous & Muscle & $\mathrm{X}$ \\
Intravenous & Skin/muscle & $\mathrm{X}$ \\
\hline
\end{tabular}

need to be transported from the site of administration into the systemic circulation. A drug is only considered to be absorbed once it has entered the blood capillaries. The transport of drugs across membranes involves one or more of the following processes: 1) passive diffusion, 2) filtration, 3) bulk flow, 4) active transport, 5) facilitated transport, 6) ion-pair transport, 7) endocytosis, and 8) exocytosis. Drug absorption also depends on a number of physicochemical factors, the two most important of which are lipophilicity and solubility. ${ }^{6,7}$ The membrane of the gastrointestinal epithelial cells is composed of tightly packed phospholipids interspersed with proteins. Thus, the transcellular passage of drugs depends on their permeability characteristics to penetrate the lipid bilayer of the epithelial cell membrane, which is in turn dependent on the lipophilicity of the drugs. Although correlations have been established between lipophilicity and increased permeability, lipophilicity is not always predictive of permeability. ${ }^{8}$

The possible sites of absorption are summarized in Table 3. A simple measure of absorption is the ratio of the concentration of a compound in blood following intravenous and nonintravenous (e.g., oral) administration. This value (also called bioavailability) is usually expressed as a percentage and is defined as the fraction of its oral dose that reaches the systemic circulation as follows:

$$
\text { Absorption }=\mathrm{D}_{\text {oral }} / \mathrm{D}_{i} \times 100
$$

Where $\mathrm{D}_{\text {oral }}$ is the distribution of a compound after oral administration and $D_{i}$ is its distribution after intravenous administration. Because the entire blood supply of the upper gastrointestinal tract passes through the liver before reaching the systemic circulation, it may be metabolized during the first passage of drug absorption (Table $3)$. A drug with high metabolic clearance is always subject to an extensive first-pass effect, resulting in low bioavailability. In addition to membrane permeability, the lipophilicity of a drug also affects metabolic activity because lipophilic compounds tend to have a greater affinity for metabolic enzymes. Thus, the greater the lipophilicity of a drug, tends to lead to both higher permeability and greater metabolic clearance. ${ }^{9}$ These opposing influences on bioavailability need to be carefully considered in the drug discovery process, particularly for CNS drugs that need to have sufficient lipophilicity to allow them to cross the BBB.

\section{Distribution}

Once in the bloodstream, the drug then distributes across the body. It is not possible to determine this directly; there is a relationship between drug concentration in blood and its volume of distribution $\left(\mathrm{V}_{\mathrm{d}}\right)$ :

$$
\mathrm{V}_{d}=\mathrm{D}_{\text {bod } y} / \mathrm{D}_{\text {blood }}
$$

Where $\mathrm{D}_{\text {body }}$ is the amount of drug in the body at any time and $\mathrm{D}_{\text {blood }}$ is the corresponding amount of drug in blood at the same time. The volume of distribution varies considerably, e.g., for furosemide it is 7 liters, whereas for mianserin it is 2800 liters.

The major determinants of the volume of distribution of a drug are the physiological spaces into which the drug distributes and the relative affinity of the drug for the blood and tissues. ${ }^{10}$

Another key measure of drug elimination is clearance, which may be defined as the theoretical volume of fluid from which a drug is completely removed in a given period of time. It can be considered at both the level of a given organ or the body as a whole. The total body clearance $\left(\mathrm{Cl}_{\mathrm{T}}\right)$ of a drug is defined by the following equation:

$$
\mathrm{Cl}_{T}=\mathrm{D}_{0} / \mathrm{AUC}
$$

Where AUC is the area under the blood concentrationtime curve. There is a clear need to predict drug clearance in humans on the basis of experimental data. ${ }^{11}$ As well as affecting the absorption and metabolism of a drug, lipophilicity also influences its binding and distribution. Generally, the higher the lipophilicity of a drug, the stronger its binding to protein and the greater its distribution.

As described earlier, once a drug enters the bloodstream it is eliminated in an exponential manner as a function of biotransformation (metabolism) and excretion.

\section{Metabolism}

The purpose of drug metabolism is to make drugs more water soluble so they can be more easily excreted from the body. There are three general types of biotransformation reactions involved in the metabolism of drugs and other foreign compounds (xenobiotics): 1) oxidation-reduction, 2) hydrolysis, and 3) conjugation. Most of these drug-metabolizing enzymes are found in the liver, but they are also found in other tissues, particularly 
TABLE 4. Summary of Xenobiotic-Metabolizing Human Hepatic Cytochrome (CYP) Enzymes

\begin{tabular}{|c|c|c|c|c|}
\hline $\begin{array}{l}\text { Cytochrome } \\
\text { P450 Isoform }\end{array}$ & $\begin{array}{l}\text { Relative Amount } \\
\text { in Liver }(\%)\end{array}$ & Substrate(s) & $\begin{array}{l}\text { Selective } \\
\text { Inhibitor(s) }\end{array}$ & $\begin{array}{l}\text { Other } \\
\text { Features }\end{array}$ \\
\hline CYP1A2 & $\approx 10$ & $\begin{array}{l}\text { Ethoxyresorufin } \\
\text { Phenacetin }\end{array}$ & Furafylline & Inducible \\
\hline CYP 2A6 & $\approx 10$ & Coumarin & Methoxalen & Polymorphic \\
\hline CYP 2B6 & $\approx 1$ & S-Mephenytoin & Orphenadrine & Polymorphic \\
\hline CYP 2C8 & $<1$ & Paclitaxel & Quercetin & Polymorphic \\
\hline CYP 2C9 & $\approx 20$ & $\begin{array}{l}\text { Tolbutamide } \\
\text { Diclofenac } \\
\text { S-Warfarin }\end{array}$ & Sulfaphenazole & Polymorphic \\
\hline CYP 2C19 & $\approx 5$ & $\begin{array}{l}\text { S-mephenytoin } \\
\text { Omeprazole }\end{array}$ & Omeprazole & Polymorphic \\
\hline CYP 2D6 & $\approx 5$ & $\begin{array}{l}\text { Dextromethorphan } \\
\text { Debrisoquine } \\
\text { Bufuralol }\end{array}$ & Quinidine & Polymorphic \\
\hline CYP 2E1 & $\approx 10$ & $\begin{array}{l}\text { Chlorzoxazone } \\
\text { Aniline }\end{array}$ & Aniline & Inducible \\
\hline CYP $3 \mathrm{~A} 4$ & $\approx 30$ & $\begin{array}{l}\text { Midazolam } \\
\text { Testosterone } \\
\text { Nifedipine }\end{array}$ & Ketoconazole & Inducible \\
\hline
\end{tabular}

the lung. Oxidative metabolism by cytochrome p450 enzymes is the primary method of drug metabolism (Table 4). These monooxygenase enzymes encompass a highly diverse superfamily of hemoproteins and are mainly located in the endoplasmic reticulum and mitochondria of cells, particularly in the liver and small intestine.

More than 60 key isoforms of cytochrome P450 are known, with hundreds of genetic variations possible, producing a wide variety of susceptibility to specific toxins. To date, at least $14 \mathrm{P}-450$ gene families have been identified in mammals. ${ }^{12}$ Although all members of this superfamily possess highly conserved regions of amino acid sequence, there are considerable variations in the primary sequences across species. There is also variation within species. For example, the CYP2C19 isoform is polymorphic, with $2-6 \%$ of Caucasians or $14-22 \%$ of Asians being poor metabolizers. ${ }^{13}$ There are also profound sex-related differences in drug metabolism. Thus, sexual dimorphism in rats, and possibly in other species, results from the differential expression of sex-dependent hepatic cytochrome P-450s. Such sex-related differences in the levels of cytochrome P-450 expression can be expected to give rise to profound differences in toxicological response because the susceptibility of a tissue to the toxic and/or carcinogenic effects of drugs often is determined by the rate of metabolic inactivation and/or activation by cytochrome P-450. For this reason, regulatory agencies require that equal numbers of males and females of each species be used in toxicity studies of drugs.

\section{Excretion}

The kidney serves as the major organ responsible for the removal of most drugs, especially those that are water soluble. Another key organ of excretion is the liver, which secretes about 1 liter of bile daily. Because the passage of xenobiotics from the blood into liver is normally not restricted, they often reach the hepatic extracellular fluid from the plasma. The passage of substances into the bile, however, is much more restrictive. Other routes of elimination include the lungs, sweat, and saliva.

\section{Drug metabolism and pharmacokinetics}

Pharmacokinetics (PK) is the mathematical description of the rates of ADME processes and of concentrationtime relationships (FIG. 2). PK plays a central role throughout pharmaceutical research and development and, because of the key role of drug metabolism, drug discovery research in this area is covered by groups

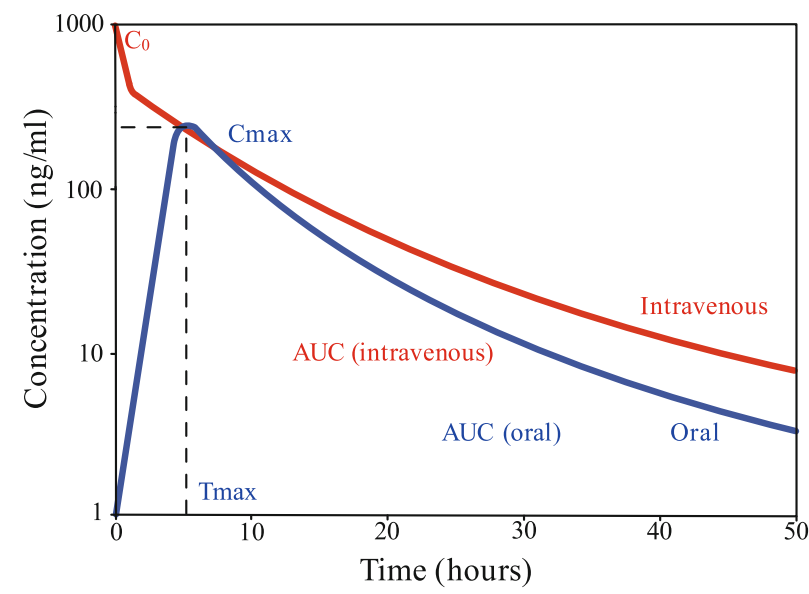

FIG. 2. Concentration-time profile in plasma following both ora and intravenous administration. Following oral administration, Tmax is the time take to achieve the maximal concentration and Cmax is the maximal concentration achieved. After intravenous administration, $\mathrm{C}_{0}$ is the extrapolated concentration at $\mathrm{t}=0$. AUC represents a measure of total drug exposure. 
coalesced around the name drug metabolism and pharmacokinetics (DMPK). ${ }^{14-18}$ Such groups were originally set up in the 1960s and 1970s to investigate the metabolism of new drug candidates in animals used for toxicology testing, and compare these findings with observations in humans. During development, DMPK has the important role of supporting the assessment of the safety and efficacy of agents, but little attention was given to drug delivery, pharmacokinetics, duration of action, metabolism, solubility, and formulation. This meant that many pharmacologically active compounds were selected whose development subsequently failed due to other factors, e.g., poor bioavailability, high clearance, low solubility, and formulation difficulties. This is supported by an analysis of the causes of failure of compounds selected for development in the 1980s. In a study of 198 new chemical entities that had undergone clinical development by large UK companies, issues relating to pharmacokinetics accounted for 39\% of the failures, with lack of efficacy accounting for a further $30 \%{ }^{19}$ However, a subsequent analysis demonstrated that if a large number of poorly bioavailable anti-infective drugs were excluded, the remaining 121 compounds had a different profile: PK issues accounted for 7\%, with lack of efficacy accounting for $46 \%$ of the failures. ${ }^{14,20}$ This analysis likely underestimates the contribution of PK issues because lack of efficacy can itself be related to PK issues, as illustrated by a preclinical analysis of the therapeutic ratios of compounds that had entered clinical trial for stroke. ${ }^{21}$ This demonstrated that many compounds had therapeutic ratios of one or less, which probably led to the administration of subtherapeutic doses to avoid the emergence of side effects. There is also the example of Gavestinel, which completed phase III clinical trials, but failed to demonstrate clear efficacy, probably because it was not able to cross the BBB. ${ }^{21,22}$

\section{Plasma half-life}

Most drugs are administered as a fixed dose, administered at regular intervals, to achieve therapeutic efficacy. Its duration of action is reflected by its plasma half-life $\left(t_{1 / 2}\right)$. Thus, the $t_{1 / 2}$ of a drug in plasma is one of the major factors to establish the optimal dosage regimen. Administration of drugs with a short $t_{1 / 2}$ requires frequent dosing and often results in poor patient compliance. Because the $t_{1 / 2}$ of a drug is determined by both its volume of distribution and its elimination clearance, the prolongation of $t_{1 / 2}$ can be achieved by increasing the volume of distribution or decreasing the clearance, or both. It is probably easier to introduce chemical modifications to slow a drug's clearance than to increase its volume of distribution. Other approaches to prolong the $t_{1 / 2}$ include sustained-release dosage forms and coadministration of inhibitors of drug-metabolizing enzymes. Metoprolol, a $\beta$-adrenergic receptor antagonist has a rel- atively short $t_{1 / 2}(<3 \mathrm{~h})$, so a once-a-day sustained-release tablet was developed. ${ }^{23}$ This sustained-release dosage form produced a more prolonged and uniform effect on the heart rate and systolic blood pressure than when given as a conventional tablet twice a day. Sinemet provides an example of coadministration of enzyme inhibitors to prolong the duration of drug action. Sinemet is widely used for the treatment of Parkinson's disease. It is a combination of L-dihydroxyphenylalanine (L-DOPA) and carbidopa. When L-DOPA is given alone, more than $90 \%$ of the dose is decarboxylated peripherally, leaving only $10 \%$ available to increase dopamine concentrations in the brain. To minimize the decarboxylation of LDOPA outside the CNS, carbidopa, a peripherally active decarboxylase inhibitor that cannot cross the BBB, is coadministered. Because of the different PK profiles of L-DOPA and carbidopa, a controlled release preparation has been produced, which offers a steadier climb to peak plasma concentrations that are less extreme and of greater duration. ${ }^{24}$

\section{Protein binding}

The intensity and duration of drug action is mediated by the time course of unbound drug concentrations at the site of action. Although direct measurement of unbound drug concentrations at the site of action is often not possible, the unbound drug concentrations in plasma often bear a proportional relation, such that unbound drug concentrations in plasma can be used in lieu of concentrations at the site of action. This assumption implies that drugs bind reversely to plasma and tissue protein and that equilibrium of unbound drug occurs readily between plasma and tissues. Although plasma protein binding of drugs has been studied for almost 100 years, accurate prediction of this ADME parameter continues to be problematic. ${ }^{25}$ There are numerous in vitro methods for the determination of protein binding, including equilibrium dialysis, dynamic dialysis, ultrafiltration, ultracentrifugation, exclusion chromatography, and circular dichroism. Because the binding of drugs to plasma proteins is an important factor in determining their pharmacokinetics and pharmacological effects, plasma protein binding is routinely determined in vitro for drugs in discovery and development. The question is whether the in vitro binding data accurately reflects the in vivo binding. Recently, microdialysis has been used to measure the unbound drug concentration in biological fluid. This permits direct measurement of plasma protein binding in vivo. ${ }^{26}$

\section{The role of DMPK in drug discovery}

The attrition rates of new chemical entities in preclinical and clinical development are very high (FIG. 1). Contributing factors include failure to demonstrate robust therapeutic efficacy, safety-related issues, and a suboptimal DMPK profile. Identifying such factors early in the drug discovery process is highly desirable, particu- 
larly because it could lower both the cost and reduce the time required to get a new drug to market. ${ }^{27}$ However, this has not yet occurred. ${ }^{28}$ The number of compounds being screened has increased substantially in the past few years, yet this has not yet led to a corresponding improvement in the efficiency or effectiveness of drug discovery. The complexity of the drug discovery process is clearly a contributing factor, along with a combination of specific (and interrelated) factors including solubility, acid dissociation constant (pKa), absorption, bioavailability, metabolism, formulation, pharmacokinetics, toxicity, and therapeutic efficacy. ${ }^{14,20}$

Thus, DMPK is playing an increasingly important role in drug discovery. ${ }^{14-18}$ In addition to potency and selectivity, drug candidates are now selected on the basis of DMPK properties, e.g., low clearance, good oral bioavailability, and an acceptable profile of metabolism in both human and nonhuman tissues. This has led to greater integration of DMPK functions into increasingly early stages of the drug discovery process. The assessment of physicochemical and pharmacological properties of candidates is now being conducted at very early stages of drug discovery to accelerate the conversion of hits and leads into qualified development candidates. In particular, in vitro ADME assays and in vivo DMPK studies are being conducted throughout the discovery process, with an aim to improve the probability of success of drug leads. $^{29}$

\section{CNS DRUG DISCOVERY}

Modern CNS drug discovery began with Daniel Bovet at the Pasteur Institute in Paris. He wanted to understand the physiological role of histamine, and realized the actions of neurotransmitters such as acetylcholine and adrenaline could be investigated much more effectively with receptor antagonists: atropine and ergotamine, respectively. Using guinea pig intestine, he therefore screened compounds that had previously been synthesized at the Institute for antihistamine activity. None of the compounds identified were sufficiently safe for human use, but in 1941 phenbenzamine was found suitable for clinical use, which led the way for a large number of antihistamine medications. Henri Laborit (a French surgeon) was one of the first to use antihistamines to prevent the traumatic consequences of shock caused by circulatory collapse during surgery. This led him to discover the important effects that antihistamines, particularly promethazine, had on the CNS. He used promethazine and found that it made patients less anxious. Laborit visited the manufacturers, Rhone-Poulenc, at Vitry-sur Siene, near Paris, and persuaded them to synthesize analogs. In the spring of 1951, Laborit was given samples of chlorpromazine. So pleased was he with the "beatific quietude" it produced that he recommended it for use in calming agitated patients. Two Parisian psychiatrists (Jean Delay and Piere Denikeer) observed clear-cut benefits in a variety of patients including agitated and/or anxious patients, hyperactive manics, and schizophrenics. ${ }^{4,5}$ Insight into the biochemical basis of this efficacy emerged from Sweden in 1962 when Arvid Carlsson demonstrated that chlorpromazine (and other neuroleptics) increase dopamine turnover. Carlsson, who was subsequently awarded the Nobel prize for his contribution to our understanding of transduction in the nervous system, suggested that they work by blocking dopamine receptors. This was subsequently confirmed by many groups worldwide. The first generation of neuroleptic drugs were shown to block $\mathrm{D}_{2}$ receptors and have made a substantial contribution to the management of schizophrenia. ${ }^{30}$ However, such compounds have a number of serious limitations. Firstly, they are not always effective. Secondly, positive psychopathological symptoms may benefit more than negative or deficit symptoms. Thirdly, antipsychotics are generally associated with a variety of adverse neurological effects; these effects were first seen with chlorpromazine, which caused persistent abnormal facial movements (tardive dyskinesia). A major advance in this area emerged in 1988 with the description, by Kane and colleagues in the United States, of a compound (clozapine) with a much reduced propensity to induce adverse neurological effects. This "atypical" antipsychotic was active at other receptor types, including $\mathrm{D}_{4}$ receptors ${ }^{31}$ and led to the emergence of a new generation of "atypical" antipsychotics during the 1990s, which have been further refined during this decade, e.g., aripiprazole (Table 5). ${ }^{32}$

\section{Anxiolytic drugs}

In addition to providing the stimulus for the development of a variety of antipsychotic medications, chlorpromazine also led to the emergence of anxiolytic drugs. At the laboratories of Hoffman-LaRoche in Nutley, NJ, in the 1950s, Leo Sternbach was examining compounds he made on the basis of introducing a basic side chain within the tricyclic structure of chlorpromazine. Out of these efforts emerged chlordiazepoxide (Librium), which was found to have a tranquilizing effect similar to that of chlorpromazine, but without the side effects. A patent was filed in May 1958 and, after initial clinical trials in 16,000 patients, this tranquilizer was granted Food and Drug Administration approval and placed on the market in 1960. A sister molecule, diazapam (Valium), was synthesized in 1959 and marketed 4 years later. This class of compound was named benzodiazepines, a term that refers to the portion of the structure composed of a benzene ring fused to a seven-membered diazepine ring. However, because all of the important benzodiazepines contain an aryl substituent ring and a 1, 4-diazepine ring, 
TABLE 5. Three Generations of Antipsychotic Drugs

First generation

Second generation

Third generation
Chlorpromazine (Thorazine)

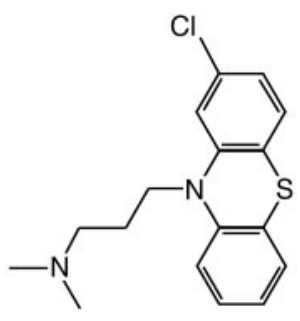

Clozapine (Clozaril)<smiles>CN1CCN(C2=Nc3cc(Cl)ccc3Nc3ccccc32)CC1</smiles>

Respiridone (Risperdal)

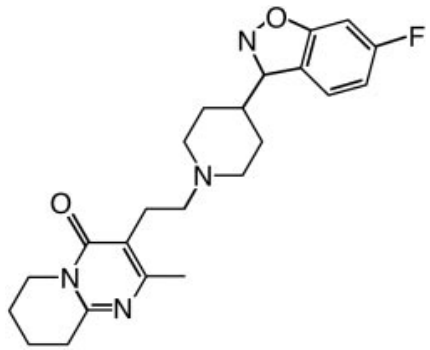

Remoxipride (Roxiam)<smiles>CCN1CCCC1CNC(=O)c1c(OC)ccc(Br)c1OC</smiles>

Aripiprazole (Abilify) the term has come to mean the aryl-1,4-benzodiazepines. 4

There is little doubt of the therapeutic efficacy of benzodiazepines in reducing anxiety, inducing sleep and quelling panic symptoms. They are widely prescribed, with four of them-alprazolam (Xanax), clonazepam (Klonopin), diazepam (Valium), and lorazepam (Ativan)-listed among the top 100 most commonly prescribed medications. ${ }^{33}$ They are relatively safe and, even when overdosed, rarely result in death, but with chronic dosing they do become addictive. ${ }^{34,35}$ As a drug class, benzodiazepines share many clinical properties, although the different agents in this class may display different pharmacokinetic and pharmacodynamic properties (Table 6). The development of physiologic dependence is predictable and proportional to the total benzodiazepine exposure.

Efforts to determine the mechanism of benzodiazepine action were initiated only after their introduction into the clinic. It was not until 1974 that convincing evidence from behavioral, electrophysiological, and biochemical experiments clearly demonstrated that benzodiazepine 
TABLE 6. Potency and Half-Life of Various Benzodiazepines

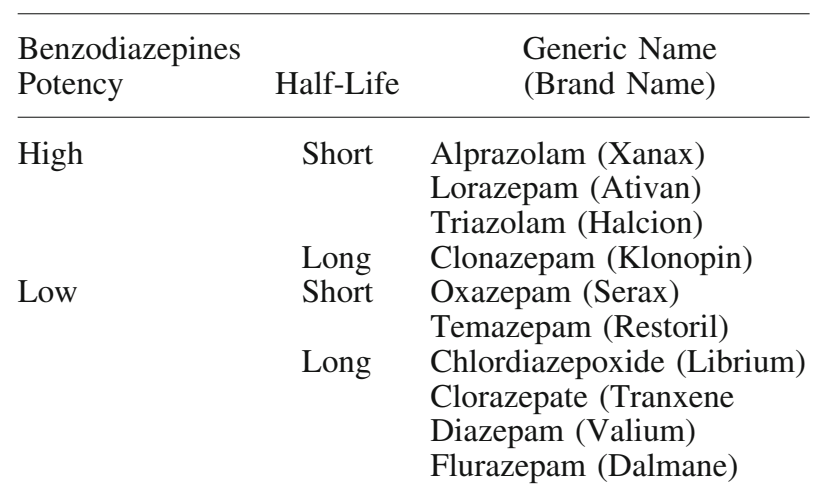

receptors are located on the $\alpha$-subunit of the GABA receptor located almost exclusively on postsynaptic nerve endings in the CNS (especially in the cerebral cortex). Benzodiazepines enhance the action of the transmitter GABA in the opening of postsynaptic chloride channels that leads to hyperpolarization of cell membranes. That is, they allosterically modify the receptor so that the effect of GABA is enhanced. In addition to their beneficial anxiolytic, muscle relaxant and anticonvulsant effects, benzodiazepines also have several undesirable side effects, including an interaction with ethanol, and memory impairment, along with a propensity to cause tolerance and dependence.

The $\mathrm{GABA}_{\mathrm{A}}$ receptor contains multiple subunits, which can coassemble in many possible pentameric permutations to form functional receptors. The most common combinations are: $\alpha 1 \beta \gamma 2, \alpha 2 \beta \gamma 2, \alpha 3 \beta \gamma 2$, and $\alpha 5 \beta \gamma 2$. Knowledge that the benzodiazepine binding site is formed by $\alpha$ - and $\gamma 2$-subunits raised the possibility that the desirable and undesirable actions of benzodiazepines could be separated. Elegant studies using knock-in mice carrying benzodiazepine binding site alterations have been used to establish that sedative, amnesic, and anticonvulsant effects are linked to the $\alpha 1$ subunit-containing $\mathrm{GABA}_{\mathrm{A}}$ receptors, anxiolytic, myorelaxant, and anticonvulsant effects to the $\alpha 2$ subunitcontaining anxiolytic (myorelaxant), and antiabsence effects to the $\alpha 3$ subunit-containing receptors and cognitive (myorelaxant) tolerance to sedative effects to receptors with $\alpha 5$ subunits. $^{36,37}$

\section{Drugs for neurodegenerative disorders}

The approach of discovering drugs on the basis of behavioral changes in experimental animals and humans is much less common today, largely because of the emergence of the rational approach of developing drugs on the basis of an understanding disease pathophysiology. This approach was pioneered by Ehringer and Hornykiewicz, who, in $1960,{ }^{38}$ demonstrated that Parkinson's disease is associated with reduced concentrations of dopamine and its major metabolite (homovanillic acid) in the striatum. This loss was subsequently found to correlate with both cell loss from the substantia nigra and two of the three cardinal symptoms of Parkinson's disease (akinesia and tremor). This laid the basis for replacement therapy. Dopamine itself was tried, but it did not cross the BBB. Dopamine's immediate precursor, L-dihydroxyphenylalanine (L-DOPA), was then used instead. L-DOPA is actively transported into the brain by the neutral amino acid transporter and, once peripheral metabolism was blocked, it was used to great effect in the treatment of Parkinson's disease. This groundbreaking work stimulated a number of other groups across the world to begin to investigate the biochemical basis of other neurodegenerative diseases. A clear consequence of this effort came from three independent groups in the UK (led by David Bowen, Peter Davies, and Elaine Perry), who in the mid 1970s demonstrated that the activity of the enzyme responsible for the synthesis of acetylcholine, choline acetyltransferase, was reduced in Alzheimer's disease. It rapidly led to the hypothesis that the dementia associated with Alzheimer's disease occurs as a consequence of dysfunction of cholinergic neurons, which established the conceptual framework for the emergence of therapies to enhance cholinergic function. More than 25 years later, inhibitors of the enzyme responsible for acetylcholine catabolism, acetylcholinesterase (AChE), have become the most successful approach, with three such compounds (donepezil, rivastigmine, and galantamine) now on the market for the symptomatic treatment of mild and moderate Alzheimer's disease. These compounds have a much better side effect profile than the first generation of AChE inhibitors (Table 7). ${ }^{39,40}$ This rational approach to therapy contrasts markedly with therapies that were used before the AChE inhibitors, e.g., hydergine, ergoloid mesylate derived from rye, which was approved for the treatment of dementia despite the fact that it efficacy is uncertain and its mechanism of action unknown. ${ }^{41}$

Like other neurologic disorders, Alzheimer's disease has a characteristic pathology and neurochemical and genetic studies have successfully presented a number of drug targets. ${ }^{42}$ By contrast, psychiatric diseases are much less tractable because there are no characteristic brain lesions, the biological basis is much less clear, the genetics are more complex and differential diagnosis is more ambiguous.

In the wake of this new confidence for a rational drug discovery came a clearer understanding of the mechanisms underlying neuronal cell death. This was dominated by the hypothesis that over activation of excitatory amino acid receptors that is responsible for most cell death in the brain. This excitotoxicity hypothesis was particularly compelling for stroke and traumatic brain 
TABLE 7. Two Generations of Acetylcholinesterase Inhibitors for the Treatment of Alzheimer's Disease

First generation

(2)

Second generation<smiles>CNC(=O)Oc1ccc2c(c1)[C@]1(C)CCN(C)[C@@H]1N2C</smiles>

Tacrine (Cognex)<smiles>Nc1c2c(nc3ccccc13)CCCC2</smiles>

Donepezil (Aricept)<smiles>COc1cc2c(cc1OC)C(=O)C(CC1CCN(Cc3ccccc3)CC1)C2</smiles>

Rivastigmine (Exelon)<smiles>CCN(C)C(=O)Oc1cccc([As](C)(C)C)c1</smiles>

Galantamine (Reminyl) injury. Such work burgeoned in the 1980s and rapidly led to many (mainly antiexcitotoxic) compounds being assessed in clinical trials for stroke and traumatic brain injury. However, no clear therapeutic efficacy was observed. ${ }^{21,43,44}$ This spectacular lack of success has led to a massive decline in drug discovery research in the area of stroke and traumatic brain injury. This may change if efficacy is observed with compounds currently in clinical trial for stroke, e.g., Cerovive (NXY-059). ${ }^{45}$

The failure of many antiexcitotoxic compounds in clinical trials was a setback to the whole field of neuroprotection research. However, with the progress in understanding the physiological, anatomical, cellular, biochemical, and molecular basis of Alzheimer's disease and Parkinson's disease, disease-modifying therapies are now a realistic prospect. ${ }^{42,46}$ Such drugs provide great potential to diminish the considerable societal burden of the large increase in those affected by neurological disorders of old age. It has been estimated that delaying the mean onset of AD by approximately 5 years would reduce the numbers of persons with $\mathrm{AD}$ by $50 \%$ by the year $2050 .^{47}$

\section{The rewards and challenges of CNS drug discovery}

CNS represents the fastest growing therapeutic segment of the pharmaceutical market, with sales in excess of $\$ 50$ billion. Many of the top-selling drugs are in the CNS segment (Table 8), so the rewards for successful CNS research and development are clearly high. However, CNS drug candidates are more likely to fail than lead compounds targeting other therapeutic areas (FIG. 1 ), and CNS drugs take longer to get to market (12-16 years) compared with a non-CNS drug (10-12 years). 
TABLE 8. Top-Selling CNS Drugs

\begin{tabular}{lllll}
\hline $\begin{array}{l}\text { Generic } \\
\text { Name }\end{array}$ & Brand Name & Therapeutic Target & \multicolumn{1}{c}{ Drug Target } & 2001 Sales (\$ Millions) \\
\hline Olanzapine & Zyprexa & Schizophrenia & DA receptor & 3087 \\
Paroxetine & Paxil/Seroxtat & Depression & 5-HT transporter & 2673 \\
Sertraline & Zoloft & Depression & 5-HT transporter & 2366 \\
Fluoxetine & Prozac & Depression & 5-HT transporter & 1990 \\
Respiridone & Risperdal & Schizophrenia & DA and 5-HT receptors & 1845 \\
Venlafaxine & Effexor & Depression & 5-HT transporter/NA transporter & 1542 \\
Bupropion & Wellbutrin & Depression & DA and NA transporters & 931 \\
Zolpidem & Stilnox & Insomnia & GABA receptor & 902 \\
Citalopram & Celexa & Depression & 5-HT transporter & 714 \\
Zolpidem & Ambien & Insomnia & GABA receptor & 704 \\
Quetiapine & Seroquel & Schizophrenia & DA and 5-HT receptors & 700
\end{tabular}

Modified from Ref. 48. DA: Dopamine.

The underlying reasons for this are complex,${ }^{49}$ but there are three major contributors:

1. The complexity of the human brain. Constituting the most complex structure known, the brain is slow to reveal its secrets. This means that our understanding of the pathophysiology or etiology (or both in many cases) of CNS disorders is far from complete.

2. Most CNS drugs cause CNS side effects. In an analysis of all the CNS drugs marketed in the UK (which are listed on www.pharmidex.com) and $75 \%$ are associated with CNS side effects (Alavijeh, M. S., and A. M. Palmer, unpublished observations).

3. To achieve therapeutic efficacy, a potential CNS therapeutic has to cross the BBB. Most small molecules and virtually all protein and peptide therapeutics do not. However, the importance of BBB research to CNS drug discovery has been under appreciated. ${ }^{50,51}$

\section{THE BLOOD-BRAIN BARRIER}

One of the most important features of the brain and spinal cord is that they are completely separated from the blood by the BBB and the blood-spinal cord barrier. It exists within the 400 miles of capillaries that course through the brain and spinal cord and is formed by a complex network of endothelial cells, astroglia, pericytes, perivascular macrophages, and a basal lamina. Clear evidence for the existence of this permeability barrier emerged in 1909 with the demonstration by Edwin Goldman (a South African-German) that a dye injected into the blood stream of a rat stained the whole body-except for the brain and spinal cord. The corollary was also true: injection of the dye into the cerebral ventricles stained the brain and spinal cord but not the rest of the body. ${ }^{52}$ This occurs because most organs of the body are perfused by capillaries lined with endothelial cells that have small pores to allow for the rapid movement of small molecules into the organ interstitial fluid from the circulation. However, the capillary endo- thelium of the brain and spinal cord lack these pores because the endothelial cells of brain capillary are sealed together by continuous tight junctions, produced by the interaction of several transmembrane proteins that project into and seal the paracellular pathway. ${ }^{53,54}$ The interaction of these junctional proteins effectively blocks the free diffusion of polar solutes from blood along these potential paracellular pathways and so denies access to brain interstitial fluid. Thus, the BBB significantly impedes entry from blood to brain of virtually all molecules, except those that are small and lipophilic or those that enters the brain through an active transport mechanism, particularly with essential nutrients, precursors, and cofactors.

It is not sufficient for a potential neurotherapeutic agent to move across the BBB-it also has to stay in the brain long enough to exert its desired action. This means that it also has to avoid being a substrate for a variety of transport proteins that work to extrude compounds from the brain. ${ }^{55,56}$ As indicated in Figure 3, there are at least six such outwardly directed active efflux mechanisms in the $\mathrm{BBB}$, the most prominent of which is a phosphorylated glycoprotein called P-glycoprotein (P-gp), a 170$\mathrm{kDa}$ member of the ATP-binding cassette (ABC) superfamily of membrane transporters, which in humans is encoded by multidrug resistance gene 1 (MDR1). P-gp is located on the apical surface of the endothelial cells of the brain capillaries toward the vascular lumen and contributes to the poor BBB penetration of a number of highly lipophilic drugs. In a study of the concentration of 32 structurally diverse CNS drugs in brain, plasma, and CSF of wild-type and (P-gp) knockout mice, only three showed marked differences in brain/plasma ratios between knockout and wild-type mice. One of these was risperidone, which illustrates that even good P-gp substrates can still be clinically useful CNS-active agents. However, for such agents, unbound plasma concentrations may need to be greater than values projected using 


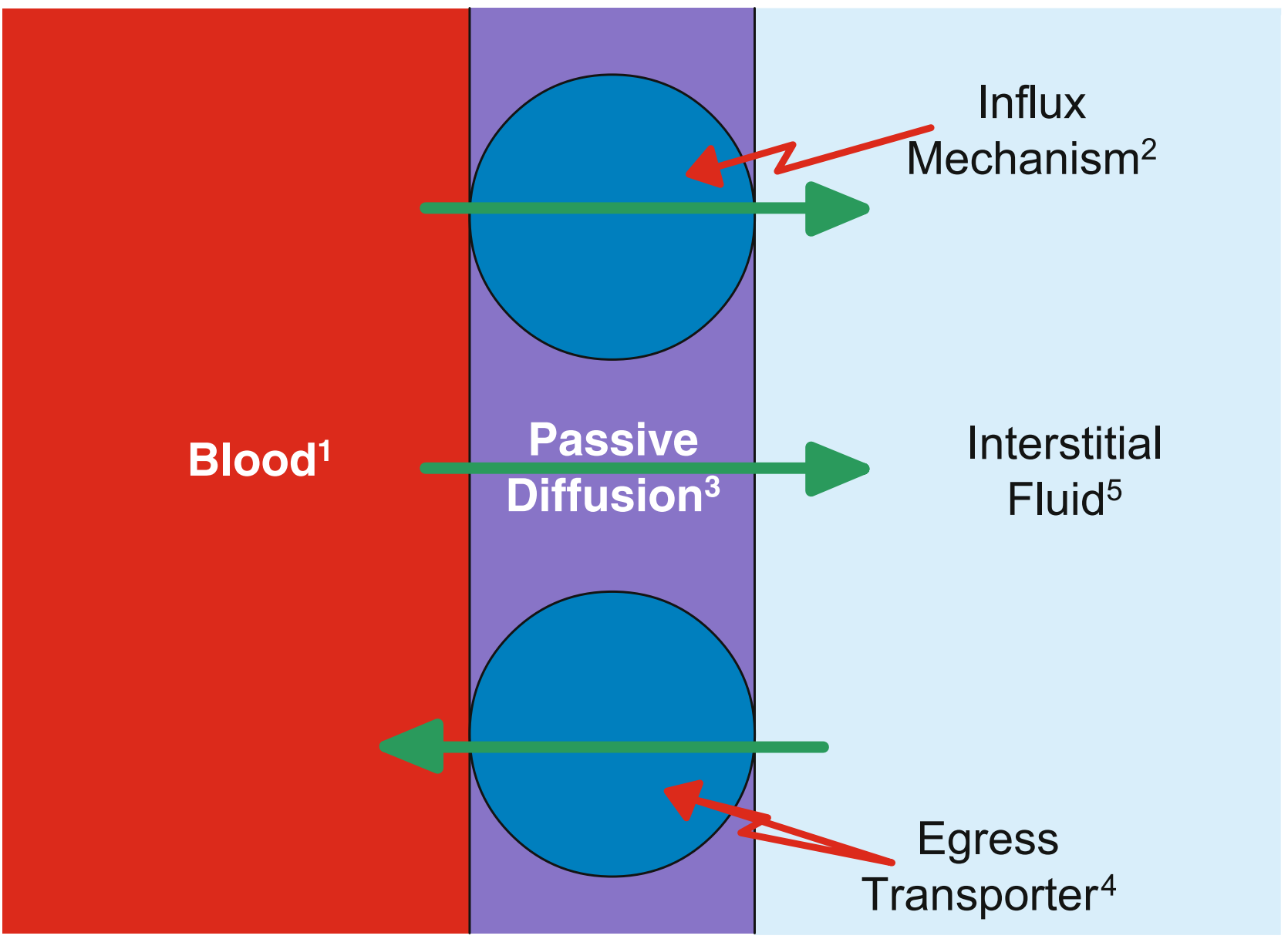

FIG. 3. Mechanisms by which molecules move across the blood-brain barrier. 1: The free concentration of a compound in blood is determined by its ADME properties, together with the extent of protein binding. 2: Influx mechanisms include: a) carrier- mediated influx (e.g., glucose, amines, amino acids, monocarboxylates, nucleosides, and small peptides), b) Receptor-mediated transcytosis (e.g., insulin and transferring), c) Absorptive-mediated transcytosis (e.g., avidin, catonized albumin and histones), d) Tight junction-mediated modulation (e.g., polar solutes). 3: Passive diffusion occurs on the basis of the physicochemical properties of molecules (see Table 8). 4: Egress transporters are able to expel a large number of chemically diverse compounds from brain interstitial fluid. BBB egress transporters include ABCB1 (multiple hydrophilic/ampiphilic, planer compounds), ABCB5, ABCC1 (anionic conjugates with glutathione, sulphate and gluconsyl, GSSH, and X-GSH), ABCC2 (anionic conjugates with glutathione), ABCC5 (organic ions, nucleotide analogs, cyclic nucleotides), ABCG2 (numerous compounds). The ABCB subfamily contains the MDR proteins, of which P-glycoprotein (P-gp) is the prototypic example. 5: A compound in the interstitial fluid can be adsorbed into brain tissue, distributed throughout the brain, metabolized by brain enzymes, or eliminated via ventricular CSF.

receptor affinity data to achieve adequate receptor occupancy for effect. ${ }^{57}$ There have been attempts to establish quantitative structure-activity relationship (QSAR) for $\mathrm{P}-\mathrm{gp},{ }^{58}$ but the task is made difficult by the broad specificity of this transporter.

\section{Ex vivo assessment of brain penetration}

In situ brain perfusion. A major approach to measure brain penetration in whole animals has been brain perfusion method of Takasatu and colleagues, ${ }^{59}$ which measures the rate of entry across brain endothelium in situ. Unlike earlier methods, such as the brain uptake index, ${ }^{60}$ which is mostly suitable for fast BBB-penetrating compounds, the brain perfusion method can be used for both slow and fast brain-penetrating compounds. The method utilizes catheterization of the common carotid artery in the anesthetized rat, together with ligation of the external carotid artery. The brain is then perfused via the internal carotid using an oxygenated physiological saline buffer containing the test substance. Once perfusion is complete, the brain is removed for analysis and uptake (volume of distribution, $\mathrm{V}_{\mathrm{d}}$ ) determined according to the following equation:

$$
\mathrm{V}_{\mathrm{d}}=\text { tissue concentration/perfusate concentration }
$$

The original procedure has been simplified by stopping endogenous blood flow through severance of the heart ventricles before commencement of brain perfusion. ${ }^{61}$ In addition to control over the perfusate composition, the perfusion technique also allows control of flow rate and perfusion duration. With a constant concentration of the 
test compound during the perfusion over time, $t$, the rate of compound transfer $\left(\mathrm{K}_{\mathrm{in}}\right)$ can be determined according to the following equation:

$$
\mathrm{K}_{\text {in }}=\mathrm{V}_{d} / \mathrm{t}
$$

In situ perfusion therefore provides a kinetic measure of the uptake of a compound into brain. The duration of perfusion with the physiological buffer can be extended up an hour by addition of oxygen carriers (e.g., washed erythrocytes), which can increase sensitivity twofold.

Brain/plasma ratio. This is a common approach in CNS drug discovery projects and provides a simple ratio of drug concentration in brain and plasma. The ratio can then be used to calculate an apparent permeability coefficient $\left(\mathrm{P}_{\text {app }}\right)$, essentially as described by Ohno and colleagues. ${ }^{62}$ It provides a simple measure of partitioning but does not take into account the presence of drug in the brain vasculature, and results are expressed as a brain/ plasma ratio.

Receptor occupancy. Another approach to assess the ability of a compound to permeate the brain substance is by determining the extent it binds to its target receptor. This measure of receptor occupancy thus also provides a very useful measure of the pharmacodynamic action of a drug. This approach has been effectively applied to a number of ligands, including compounds that bind to the $\mathrm{GABA}_{\mathrm{A}}$ receptor subtype selective benzodiazepine site. ${ }^{63,64}$ This method uses pharmacokinetic/receptor occupancy data to permit reliable interpretation of pharmacodynamic responses at a given dose

\section{In vivo assessment of brain penetration}

In situ perfusion provides a kinetic measure of brain uptake, whereas the brain/plasma ratio approach provides a partition measure. However, neither approach provides a full PK profile [i.e., maximal concentration (Cmax), half-life, and AUC] or takes account of brain egress mechanisms (e.g., via P-gp).

Sampling ventricular CSF. CSF concentrations provide a good measure of free drug concentrations in brain and can be performed post mortem or by repeated sampling of CSF from the cisterna magna in vivo. This approach was first introduced in $1992^{65}$ and has been used extensively since then. ${ }^{66} \mathrm{CSF}$ concentrations follow the same profile as that of interstitial concentrations, ${ }^{67}$ but this is not always the case. ${ }^{68} \mathrm{CSF}$ concentrations have also been shown to correlate with both brain interstitial concentrations and behavioral changes (FIG. 4).

Tissue microdialysis. The key compartment for a CNS drug is the brain interstitial fluid (FIG. 5), which can be assessed by tissue microdialysis. ${ }^{67}$ The application of tissue microdialysis to establish a full brain PK profile emerged in more than a decade ago with the study of Alavijeh and colleagues, ${ }^{69}$ which described the neuropharmacokinetic profile of the antiepileptic drug car-
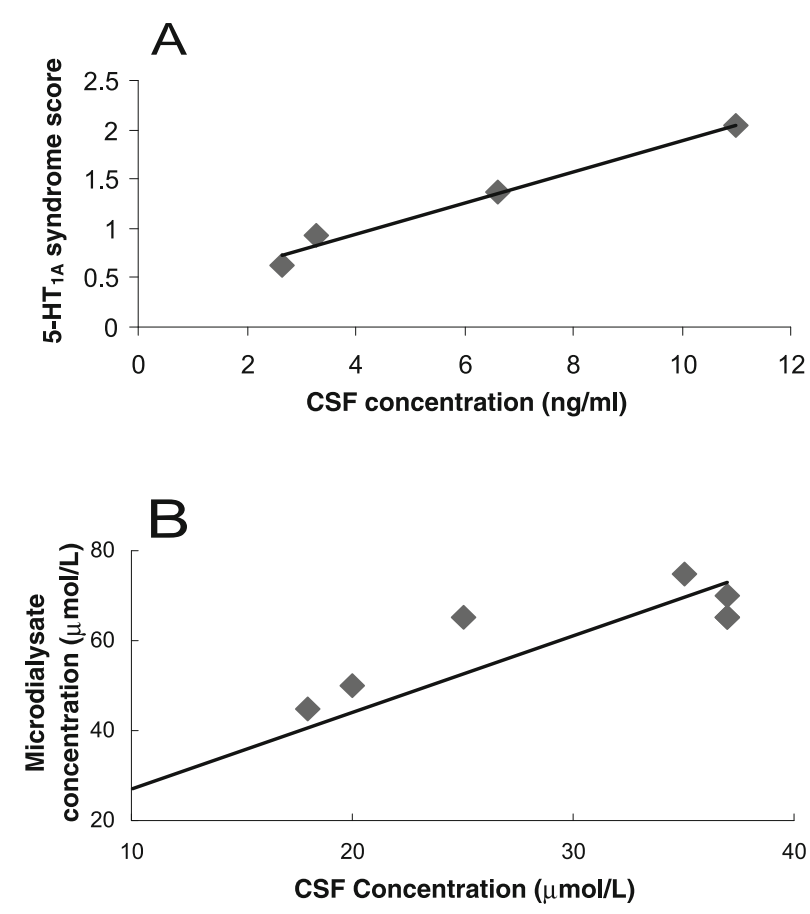

FIG. 4. Concentration of compounds ventricular CSF correlates with A) behavior and B) interstitial concentrations. A: The relationship between the concentration of a $5-\mathrm{HT}_{1 \mathrm{~A}}$ antagonist (WAY-100635) and an assessment of the behavioral syndrome evoked by the $5-\mathrm{HT}_{1 \mathrm{~A}}$ agonist 8-hydroxy-2-(di-n-propylamino)tetralin (8-OH-DPAT). B: The concentration of lamotrigine in ventricular CSF and brain interstitial fluid correlate (Alavijeh, M. S., and A. M. Palmer, unpublished observations).

bamazepine in freely moving animals. The approach was subsequently refined ${ }^{70}$ and has since been used extensively to provide critical information for CNS drug discovery. ${ }^{71-73}$ Tissue microdialysis permits measurement of the concentration of a compound in brain interstitial fluid over time, allowing Cmax, $t_{1 / 2}$, and AUC to be calculated. These quantitative measures provide a solid basis to select drug candidates with the best brain exposure profile. Microdialysis also permits a level of anatomical precision that is not available with any other method. Thus, a microdialysis probe can be stereotaxically placed into the brain region relevant to the brain disorder under investigation. This is important because systemically administered compounds do not distribute

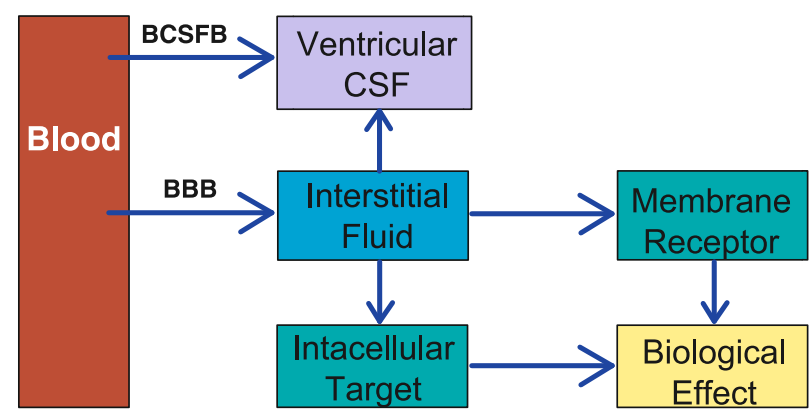

FIG. 5. Interstitial fluid is the key compartment for the action of a neuroactive compound. 


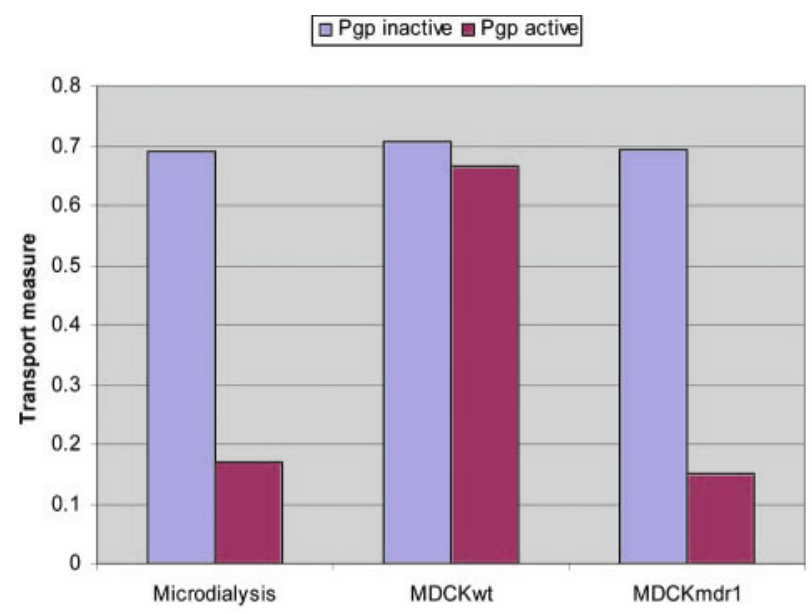

FIG. 6. In vivo and in vitro brain penetration profile of compounds that are P-gp substrates (cimetidine and morphine) with those that are not (antipyrine, caffeine, and warfarine); zidovudine ( $3^{\prime}$-azido-3'-deoxythymidine; AZT) was excluded because it appears to be effluxed out of the brain by transporters other than $\mathrm{P}$-gp. ${ }^{80}$ In vivo measures represent ratios between area under curve (AUC) obtained in brain and blood using microdialysis $\left(A \cup C_{\text {brain }} / \mathrm{AUC}_{\text {blood. }}\right.$ In vitro data represent ratios between Papp obtained in vitro for the apical to basolateral (Ap > B1) and basolateral to apical $(\mathrm{B} 1>\mathrm{Ap})$ directions. Data derived from Table 16 of Ref. 81.

evenly across the brain. Rather, there is up to a 20 -fold variation in distribution across different brain regions. This has be illustrated by a study of several regions of postmortem human brain where L-mepromazine attained highest concentrations in the basal ganglia, possibly because of the low expression of the metabolic enzyme Cyp2D6 in this region. ${ }^{74}$ Other factors that can contribute to a differential distribution across the brain include differences in blood flow and expression of transporter proteins and variability in the permeability of the BBB. Measuring the concentration of a drug candidate at its site of action is a key element in the CNS drug discovery process. In addition to increasing the probability of success, it also permits optimal dosing in subsequent preclinical and clinical studies, which facilitates more rapid progress to market. With an optimal dosing regimen in place for preclinical studies, it may be possible to optimize efficacy and diminish side effects and improve the therapeutic ratio of a drug candidate. Similarly, the dosing regimen of a compound in clinical studies is based on the PK profile in blood, which can be very misleading because it is possible for a compound to have a long half-life in blood, but a short half-life in brain-or even not to penetrate the BBB at all. ${ }^{21}$

Another advantage of microdialysis is that it can be used to assess pharmacodynamic measures, which thus permits neuropharmacokinetic profile of a compound to be related to its neuropharmacodynamic profile. Thus, for example, in a microdialysis study using a potent and selective serotonin transport inhibitor (of BMS-505130) changes in its interstitial concentrations mirrored changes in the interstitial concentrations of serotonin. ${ }^{75}$ Further validation of the microdialysis method is provided by a study showing that increased concentrations of extracellular dopamine in the human amygdala during the performance of cognitive tasks. ${ }^{76}$

Imaging in humans. In addition to ex vivo studies of receptor occupancy, positron emission tomography (PET) using receptor ligands containing a positron-emitting isotope permit receptor occupancy studies to be carried out in the intact human brain. Thus, for example, $\left[{ }^{18} \mathrm{~F}\right] 6$-fluoro-L-DOPA-PET and dopamine receptor imaging by PET have been shown to be altered in Parkinson's disease. These changes not only assist in the differential diagnosis of various forms of parkinsonism, but they are also capable of detecting subclinical dopaminergic deficits. ${ }^{77}$ Similarly, on the basis of an assessment of dopamine D2 receptor function, using $\left[{ }^{11} \mathrm{C}\right]$ raclopride, it has been shown that identical doses of L-DOPA induce greater changes in the synaptic concentration of dopamine as Parkinson's disease progresses. Large L-DOPAinduced increases in synaptic dopamine concentration can lead to dramatic changes in receptor occupancy, which may be responsible for the emergence of peakdose dyskinesias in Parkinson's disease. ${ }^{78}$ The observed pharmacodynamic changes observed in such studies probably reflect changes in the neuropharmacokinetic profile. Although few PET studies have measured the neuropharmacokinetic profile directly, an exciting new approach is to use quantitative PET measurement to assess P-gp function, which has the potential to optimize dosing regimens. ${ }^{79}$

\section{In vitro assessment of brain penetration}

Numerous in vitro models of the BBB have been established, including primary bovine and human brain endothelial cells cocultured with astrocytes, immortalized brain endothelial cell lines, along with models using cells not derived from endothelial cells, which include kidney cells [e.g., Madin-Darby canine kidney (MDCK) cell lines] and intestinal epithelial cells (e.g., Caco-2 cell lines). ${ }^{76,81-85}$ The essential features of in vitro models of the $\mathrm{BBB}$ is that they reproduce key features of the intact $\mathrm{BBB}$ and, most importantly, that a positive result in such a model effectively predicts brain penetration in vivo. The model must therefore have both good construct validity and good predictive validity. In a recent comprehensive comparison of numerous in vitro models, it was MDCK cells that offered the best model in terms of predicting $\mathrm{BBB}$ penetration based on microdialysis data. ${ }^{81}$ This is supported by data showing good correlations with brain permeation assessed using the in situ perfusion method. ${ }^{81,86,87}$ MDCK cells thus have good predictive validity. They also have good construct validity because, like the intact BBB (unlike most endothelial cell models), these cells have a transmembrane resistance. 
TABLE 9. Comparison of Blood-Brain Barrier Permeability, P-Glycoprotein Activity, and Physicochemical Properties of 48 CNS and 45 Non-CNS Drugs

\begin{tabular}{lccc}
\hline & CNS & Non-CNS & CNS as \% of Non-CNS \\
\hline Molecular weight & 319 & 330 & 97 \\
Passive $\mathrm{P}_{\text {app }}(\mathrm{nm} / \mathrm{s})^{\mathrm{a}}$ & 474 & 331 & $143^{*}$ \\
$\%$ P-gp substrates & 15 & 42 & $35^{*}$ \\
Hydrogen bond donors & 0.85 & 1.56 & $54^{* *}$ \\
Hydrogen bond acceptors & 3.56 & 4.51 & 79 \\
Number of aromatic rings & 1.92 & 1.93 & 99 \\
clogP $^{\mathrm{b}}$ & 3.43 & 2.78 & $123^{* *}$ \\
clogD $^{\mathrm{c}}$ & 2.08 & 1.07 & $194^{*}$ \\
Polar surface area & 40.5 & 56.1 & 72 \\
Flexibility & 1.27 & 2.18 & $58^{* *}$ \\
Positive charge & 1.19 & 1.53 & 78 \\
Negative charge & 0.00 & 0.09 & NA** \\
\hline
\end{tabular}

Data derived from reference from Ref. 88. Asterisks indicate significant difference between groups. *, $\mathrm{p}<0.05 ; * *, \mathrm{p}<0.001 . \mathrm{NA}=$ not

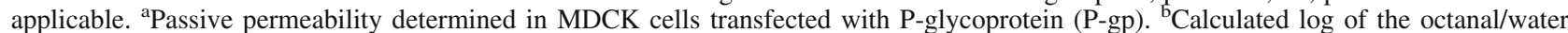
partition partition coefficient, which provides a measure of lipophilicity. ${ }^{\mathrm{c}}$ Calculated log of the distribution coefficient, which is the ratio of the sum of the concentrations of all species of the compound in octanol to the sum of the concentrations of all species of the compound in water. Like cLog P, it also provides a measure of lipophilicity

The utility of these cells for BBB research has been further enhanced by engineering them to overexpress P-gp. MDCK cells transfected with human P-gp (MDR1) have been shown to effectively discriminate compounds that cross the BBB but are not P-gp substrates from those that cross the BBB but are P-gp substrates and thus effectively predicted those that attain a high concentration in brain interstitial fluid (FIG. 6). This profile contrasts with that seen with most endothelial cell models, which do not have tight junctions and poorly predict brain penetration. However, the endothelial cells express a greater repertoire of transporter molecules, which makes them much better suited for studies investigating different transporters. In summary, because MDCK cells have a high transmembrane resistance, this model is useful to assess passive diffusion across the BBB. This, along with the ability to also assess P-gp transport, makes them a very useful model to assess the BBB permeation of compounds and the extent of outwardly directed active efflux. This has been elegantly illustrated by a comparison of apparent permeability $\left(\mathrm{P}_{\text {app }}\right)$ and P-gp substrate profiles for 93 CNS $(\mathrm{n}=48)$ and nonCNS $(n=45)$ drugs. The CNS drugs had $\mathrm{P}_{\text {app }}$ values $43 \%$ higher than non-CNS drugs and $65 \%$ less P-gp activity (Table 9).

\section{In silico prediction of $\mathrm{BBB}$ permeation}

For CNS drug discovery, it is clearly essential to establish whether a compound will penetrate and distribute within the CNS because efficacy is largely dependent on sufficient exposure within the CNS. The corollary is also true, for a non-CNS drug discovery project, it is desirable to establish that lead compounds are not likely to penetrate and distribute within the CNS and therefore have a liability to cause CNS side effects. There has, therefore, been great interest in establishing the key determinants of passive entry into the CNS, mainly using physicochemical properties. ${ }^{89-98}$ The ease with which any particular drug diffuses across the BBB (and the blood-CSF barrier) is determined largely by the number and strength of intermolecular forces binding it to surrounding water molecules. By quantifying the molecular features that contribute to these forces, it should be possible to predict the in vivo BBB permeability. On the basis of a comparison of the physicochemical properties of marketed CNS and CNS-inactive drugs, van de Waterbeemd and colleagues ${ }^{89}$ have concluded that to enhance CNS penetration, a compound should have a molecular weight below 450 and a total polar surface area of at least $90 \AA$. This study has been confirmed and extended by a more recent comparison of CNS and non-CNS drugs (Table 9). Other studies have correlated brain uptake with lipophobicity, hydrogen donors/acceptors, and the number of rotatable bonds. $^{90,91}$

In silico prediction methods offer the prospect of screening libraries of actual or virtual compounds on the basis of BBB permeation. A number of such models are available. They have evolved from simple regression models based on calculation of lipophilicity and polar surface area, to grid-based approaches; the use of artificial neural networks is also becoming very popular. ${ }^{91,95}$

An in silico model of the BBB is clearly not going to have any construct validity, so its utility rests entirely with its power of prediction. However, because of the paucity consistent brain permeation data, effective modeling is difficult and the utility of the models questionable. What is needed is an algorithm that has been informed and improved on the basis of BBB permeation data obtained using both in vitro and in vivo models. 
P-gp is an important impediment for the entry of hydrophobic drugs into the brain, so proper prediction models should also take into account the active transport phenomena. A QSAR model of P-gp activity has been developed to predict whether a given compound is a P-gp substrate or not. ${ }^{58}$

\section{CONCLUSIONS}

The past 50 years has seen considerable progress in our understanding of the physiological, anatomical, cellular, biochemical, and molecular basis of CNS disorders, along with the emergence of modern CNS drug discovery. CNS drugs represent one of the largest segments of the total drug market, and it constitutes the segment with the greatest potential for substantial growth in the years ahead, largely because of the rapidly increasing numbers of individuals with CNS disorders. However, most CNS disorders are not treated well, if at all, and the time taken for CNS drugs to get to market is longer than other therapeutic areas, and the probability of getting to market is lower. Thus, there is a clear need for CNS drug discovery to become more efficient and more effective in order to meet the burgeoning need for CNS therapeutics. A number of bottlenecks have been identified: one of the key factors is the failure to pay sufficient attention to the prediction and assessment of the ability of compounds to cross the BBB. ${ }^{49-51}$

Acknowledgments: We thank Steven Palmer for his expert assistance in the preparation of the figures and tables and Jennifer Hawton for her help in constructing Table 9.

\section{REFERENCES}

1. Palmer AM, DeKosky ST. Neurochemistry of ageing. In: Principles and practice of geriatric medicine (Pathy MSJ, ed), Ed 4, pp 65-76. London, UK: Wiley Ltd., 1998.

2. Is the pharma industry weathering the 'perfect storm'? IMS Health, 17 March 2003.

3. Philips SP, Mackintosh A. Beyond 2005. the future of pharmaceutical marketing and sale. Perspective on life sciences. Special edition. Chichester, Sussex, UK: Ernst \& Young, 2002.

4. Sneader W. Drug discovery-a history. Chichester, Sussex, UK: Wiley, 2005.

5. Snyder SH. Drugs and the brain. New York: Palmgrave PublishersThe Scientific American Library, 1996.

6. Mannhold R. The impact of lipophilicity in drug research: a case report on $\beta$-blockers. Mini Rev Med Chem 5:197-205, 2005.

7. Bergstrom CA. In silico predictions of drug solubility and permeability: two rate-limiting barriers to oral drug absorption. Basic Clin Pharmacol Toxicol 96:156-161, 2005.

8. Avdeef A. Physicochemical profiling (solubility, permeability and charge state). Curr Top Med Chem 1:277-351, 2001.

9. Riley RJ, Parker AJ, Trigg S, Manners CN. Development of a generalized, quantitative physicochemical model of CYP3A4 inhibition for use in early drug discovery. Pharm Res 18:652-655, 2001.

10. van de Waterbeemd $\mathrm{H}$. Which in vitro screens guide the prediction of oral absorption and volume of distribution? Basic Clin Pharmacol Toxicol 96:162-166, 2005.
11. Tang H, Mayersohn MA. Novel model for prediction of human drug clearance by allometric scaling. Drug Metab Dispos 33:297303, 2005.

12. Raucy JL, Allen SW. Recent advances in P450 research. Pharmacogenom J 1:178-186, 2001.

13. Wilkinson GR. Drug metabolism and variability among patients in drug response. N Engl J Med 352:2211-2221, 2005.

14. Alavijeh MS, Palmer AM. The pivotal role of drug metabolism and pharmacokinetics in the discovery and development of new medicines. IDrugs 7:755-763, 2004.

15. Roberts SA. Drug metabolism and pharmacokinetics in drug discovery. Curr Opin Drug Discov Dev 6:66-80, 2003.

16. Riley RJ, Martin IJ, Cooper AE. The influence of DMPK as an integrated partner in modern drug discovery. Curr Drug Metab 3:527-550, 2002.

17. Lin J, Sahakian DC, de Morais SM, Xu JJ, Polzer RJ, Winter SM. The role of absorption, distribution, metabolism, excretion and toxicity in drug discovery. Curr Top Med Chem 3:1125-1154, 2003.

18. Eddershaw PJ, Beresford AP, Bayliss MK. ADME/PK as part of a rational approach to drug discovery. Drug Discov Today 5:409414, 2000.

19. Prentis RA, Lis Y, Walker SR. Pharmaceutical innovation by the seven UK-owned pharmaceutical companies (1964-1985). Br J Clin Pharmacol 25:387-396, 1988.

20. Kubinyi H. Drug research: myths, hype and reality. Nat Rev Drug Discov 2:665-668, 2003.

21. Dawson DA, Wadsworth G, Palmer AM. A comparative assessment of the efficacy and side effect liability of neuroprotective compounds in experimental stroke. Brain Res 892:344-350, 2001.

22. Sacco RL, DeRosa JT, Haley EC Jr, Levin B, Ordronneau P, Phillips SJ, et al. Glycine antagonist in neuroprotection. Americas Investigators. Glycine antagonist in neuroprotection for patients with acute stroke: GAIN Americas: a randomized controlled trial. JAMA 285:1719-1728, 2001.

23. Harron DW, Shanks RG. Comparison of the duration of effect of metoprolol and a sustained release formulation of metoprolol (betaloc-SA). Br J Clin Pharmacol 11:518-520, 1981.

24. Sage JI, Mark MH. Pharmacokinetics of continuous-release carbidopa/levodopa. Clin Neuropharmacol 17:S1-S6, 1994.

25. Kratochwil NA, Huber W, Muller F, Kansy M, Gerber PR. Predicting plasma protein binding of drugs-revisited. Curr Opin Drug Discov Dev 7:507-512, 2004.

26. Huang Y, Zhang Z. Binding study of drug with bovine serum album using a combined technique of microdialysis with flowinjection chemiluminescent detection. J Pharm Biomed Anal 35: 1293-1299, 2004.

27. DiMasi JA. The value of improving the productivity of the drug development process: faster times and better decisions. Pharmacoeconomics 20:1-10, 2002.

28. US Department of Health and Human Services, Food and Drug Administration. Challenge and opportunity on the critical path of new medical products. http://www.fda.gov/oc/initiatives/criticalpath/whitepaper.html.

29. Kassel DB. Applications of high-throughput ADME in drug discovery. Curr Opin Chem Biol 8:339-345, 2004.

30. Grunder G, Carlsson A, Wong DF. Mechanism of new antipsychotic medications: occupancy is not just antagonism. Arch Gen Psychiatry 60:974-677, 2003.

31. Seeman P. Therapeutic receptor-blocking concentrations of neuroleptics. Int Clin Psychopharmacol 10:5-13, 1995.

32. Newcomer JW. Second-generation (atypical) antipsychotics and metabolic effects: a comprehensive literature review. CNS Drugs [19 Suppl 1]:1-93, 2005.

33. American Druggist. Top 200 drugs of 1995. New York: Hearst Corp., 18-26, 1996.

34. O'brien CP. Benzodiazepine use, abuse, and dependence. Clin Psychiatry 66:28-33, 2005.

35. Longo LP, Johnson B. Addiction: Part I. Benzodiazepines-side effects, abuse risk and alternatives. Am Fam Phys 61:2121-2128, 2000.

36. Whiting PJ. The $\mathrm{GABA}_{\mathrm{A}}$ receptor gene family: new opportunities 
for drug development. Curr Opin Drug Discov Dev 6:648-657, 2003.

37. Atack JR. Anxioselective compounds acting at the GABA(A) receptor benzodiazepine binding site. Curr Drug Targets CNS Neurol Disord 2:213-232, 2003.

38. Ehringer H, Hornykiewicz O. Distribution of noradrenaline and dopamine (3-hydroxytyramine) in the human brain and their behavior in diseases of the extrapyramidal system. Klin Wochenschr 38:1236-1239, 1960.

39. Palmer AM. Cholinergic therapies for Alzheimer's disease: progress and prospects. Curr Opin Invest Drugs 4:833-840, 2003.

40. Wilkinson DG, Francis PT, Schwam E, Payne-Parrish J. Cholinesterase inhibitors used in the treatment of Alzheimer's disease: the relationship between pharmacological effects and clinical efficacy. Drugs Aging 21:453-478, 2004.

41. Olin J, Schneider L, Novit A, Luczak S. Hydergine for dementia. Cochrane Database Syst Rev CD000359, 2001.

42. Palmer AM. Pharmacotherapy for Alzheimer's disease: progress and prospects. Trends Pharmacol Sci 23:426-433, 2002.

43. Muir KW, Lees KR. Excitatory amino acid antagonists for acute stroke. Cochrane Database Syst Rev CD001244, 2003.

44. Hoyte L, Barber PA, Buchan AM, Hill MD. The rise and fall of NMDA antagonists for ischemic stroke. Curr Mol Med 4:131-136, 2004.

45. Green AR, Ashwood T. Free radical trapping as a therapeutic approach to neuroprotection in stroke: experimental and clinical studies with NXY-059 and free radical scavengers. Curr Drug Targets CNS Neurol Disord 4:109-118, 2005.

46. Johnston TH, Brotchie JM. Drugs in development for Parkinson's disease. Curr Opin Invest Drugs 5:720-726, 2004.

47. Evans DA, Funkenstein HH, Albert MS, Scherr PA, Cook NR, Chown MJ, et al. Prevalence of Alzheimer's disease in a community population of older persons. Higher than previously reported. JAMA 262:2551-2556, 1989.

48. Zambrowicz BP, Sands AT. Knockouts model the 100 best-selling drugs-will they model the next 100? Nat Rev Drug Discov 2:3851, 2003.

49. Palmer AM, Stephenson FA. CNS drug discovery: challenges and solutions. Drugs News Perspect 18:51-57, 2005.

50. Pardridge WM. The blood-brain barrier: bottleneck in brain drug development. NeuroRx 2:3-14, 2005.

51. Alavijeh MS, Palmer AM. Population ageing: a challenge for CNS drug discovery. GOR 7:46-48, 2005.

52. Clarke E, O'Malley CD. The human brain and spinal cord. A historical study illustrated by writings from antiquity to the twentieth century. Berkley, CA: University of California Press, 1968.

53. Ballabh P, Braun A, Nedergaard M. The blood-brain barrier: an overview: structure, regulation, and clinical implications. Neurobiol Dis 16:1-13, 2004.

54. Abbott NJ. Dynamics of CNS barriers: evolution, differentiation, and modulation. Cell Mol Neurobiol 25:5-23, 2005.

55. Begley DJ. ABC transporters and the blood-brain barrier. Curr Pharm Des 10:1295-1312, 2004.

56. Loscher W, Potschka H. Brain barrier active efflux transporters: ATP-binding cassette gene family. NeuroRx 2:86-98, 2005.

57. Doran A, Obach RS, Smith BJ, Hosea NA, Becker S, Callegari E, et al. The impact of P-glycoprotein on the disposition of drugs targeted for indications of the central nervous system: evaluation using the MDR1A/1B knockout mouse model. Drug Metab Dispos 33:165-174, 2005.

58. Gombar VK, Polli JW, Humphreys JE, Wring SA, Serabjit-Singh CS. Predicting P-glycoprotein substrates by a quantitative structure-activity relationship model. J Pharm Sci 93:957-968, 2004.

59. Takasato Y, Rapoport SI, Smith QR. An in situ brain perfusion technique to study cerebrovascular transport in the rat. Am J Physiol (Lond) 247:H484-H493, 1984.

60. Oldendorf WH. Measurment of brain uptake of radiolabeled substances using a tritiated water internal standard. Brain Res 24:372376, 1970.

61. Deane R, Bradbury MW. Transport of lead-203 at the blood-brain barrier during short cerebrovascular perfusion with saline in the rat. J Neurochem 54:905-914, 1990.
62. Ohno K, Pettigrew KD, Rapoport SI. Lower limits of cerebrovascular permeability to non-electrolytes in the concious rat. $\mathrm{Am} \mathrm{J}$ Physiol (Lond) 235:H299-H307, 1978.

63. Scott-Stevens P, Atack JR, Sohal B, Worboys P. Rodent pharmacokinetics and receptor occupancy of the $\mathrm{GABA}_{\mathrm{A}}$ receptor subtype selective benzodiazepine site ligand L-838417. Int J Neuropsychopharmacol 8:27-36, 2005.

64. Atack JR, Alder L, Cook SM, Smith AJ, McKernan RM. In vivo labelling of $\alpha 5$ subunit-containing $\operatorname{GABA}(\mathrm{A})$ receptors using the selective radioligand [(3)H]L-655,708. Neuropharmacology 49:220-229, 2005.

65. Patsalos PN, Alavijeh MS, Semba J, Lolin YI. A freely moving and behaving rat model for the chronic and simultaneous study of drug pharmacokinetics (blood) and neuropharmacokinetics (cerebrospinal fluid): hematological and biochemical characterization and kinetic evaluation using carbamazepine. J Pharmacol Toxicol Methods 28:21-28, 1992.

66. Artru AA, Adkison KK. Principles and applicability of CSF sampling for the assessment of CNS drug delivery and pharmacodynamics. Adv Drug Deliv Rev 56:1825-1857, 2004.

67. Walker MC, Tong X, Perry H, Alavijeh MS, Patsalos PN. Comparison of serum, cerebrospinal fluid and brain extracellular fluid pharmacokinetics of lamotrigine. Br J Pharmacol 130:242-248, 2000.

68. Wang X, Ratnaraj N, Patsalos PN. The pharmacokinetic interrelationship of tiagabine in blood, cerebrospinal fluid and brain extracellular fluid (frontal cortex and hippocampus). Seizure 13: 574-581, 2004.

69. Alavijeh MS, Patsalos PN. A freely behaving animal model for the chronic and simultaneous study of pharmacokinetics and neuropharmacokinetics of drugs: an evaluation of carbamazepine (CBZ). Acta Neurologica Scandinavica 82 [Suppl 133]:S50, 1990.

70. Patsalos PN, Abed WT, Alavijeh MS, O'Connell MT. The use of microdialysis for the study of drug kinetics: some methodological considerations illustrated with antipyrine in rat frontal cortex. $\mathrm{Br} \mathrm{J}$ Pharmacol 115:503-509, 1995.

71. de Lange EC, de Boer AG, Breimer DD. Methodological issues in microdialysis sampling for pharmacokinetic studies. Adv Drug Deliv Rev 45:125-148, 2000.

72. Shen DD, Artru AA, Adkison KK, Hammarlund-Udenaes M. The use of microdialysis in CNS drug delivery studies. Pharmacokinetic perspectives and results with analgesics and antiepileptics. Adv Drug Deliv Rev 45:283-294, 2000.

73. Bickel U. How to measure drug transport across the blood-brain barrier. NeuroRx 2:15-26, 2005.

74. Kornhuber J, Weigmann H, Rohrich J, Wiltfang J, Bleich S, Meineke I, Zochling R, Hartter S, Riederer P, Hiemke C. Region specific distribution of levomepromazine in the human brain. $J$ Neural Transm, in press.

75. Fried I, Wilson CL, Morrow JW, Cameron KA, Behnke ED, Ackerson LC, Maidment NT. Increased dopamine release in the human amygdala during performance of cognitive tasks. Nat Neurosci 4:201-206, 2001.

76. Taber MT, Wright RN, Molski TF, Clarke WJ, Brassil PJ, Denhart DJ, Mattson RJ, Lodge NJ. Neurochemical, pharmacokinetic, and behavioral effects of the novel selective serotonin reuptake inhibitor BMS-505130. Biochem Behav 80:521-528, 2005.

77. Shinotoh H, Calne DB. The use of PET in Parkinson's disease. Brain Cogn 28:297-310, 1995.

78. de la Fuente-Fernandez R, Sossi V, Huang Z, Furtado S, Lu JQ, Calne DB, et al. Levodopa-induced changes in synaptic dopamine levels increase with progression of Parkinson's disease: implications for dyskinesias. Brain 127:2747-2754, 2004.

79. Elsinga PH, Hendrikse NH, Bart J, van Waarde A, Vaalburg W. Positron emission tomography studies on binding of central nervous system drugs and p-glycoprotein function in the rodent brain. Mol Imaging Biol 7:37-44, 2005.

80. Jorajuria S, Dereuddre-Bosquet N, Becher F, Martin S, Porcheray F, Garrigues A, Mabondzo A, Benech H, Grassi J, Orlowski S, Dormont D, Clayette P. ATP binding cassette multidrug transporters limit the anti-HIV activity of zidouvudine and indinavir in infected human macrophages. Antivir Ther 9:519-528, 2004.

81. Garberg P, Ball M, Borg N, Cecchelli R, Fenart L, Hurst RD, 
Lindmark T, Mabondzo A, Nilsson JE, Raub TJ, Stanimirovic D, Terasaki T, Oberg JO. In vitro models for the blood-brain barrier. Toxicol In Vitro 19:299-334, 2005.

82. Deli MA, Abraham CS, Kataoka Y, Niwa M. Permeability studies on in vitro blood-brain barrier models: physiology, pathology, and pharmacology. Cell Mol Neurobiol 25:59-127, 2005.

83. Reichel A, Begley DJ, Abbott NJ. An overview of in vitro techniques for blood-brain barrier studies. Methods Mol Med 89:307324, 2003.

84. Cucullo L, Aumayr B, Rapp E, Janigro D. Drug delivery and in vitro models of the blood-brain barrier. Curr Opin Drug Discov Dev 8:89-99, 2005.

85. Terasaki T, Ohtsuki S, Hori S, Takanaga H, Nakashima E, Hosoya K. New approaches to in vitro models of blood-brain barrier drug transport. Drug Discov Today 8:944-954, 2003.

86. Polli JW, Humphreys JE, Wring SA, Burnette TC, Read KD, Hersey A, Butina D, Bertolotti L, Pugnaghi F, Serajit-Singh CJ. Comparison of MDCK and bovine brain endothelial cells (BBECs) as a blood-brain barrier screen in early drug discovery. In: Progress in the reduction, refinement and replacement of animal experimentation (Balls M, van Zeller A-M, Halder M, eds). New York: Elsevier Science, 2000.

87. Wang Q, Rager JD, Weinstein K, Kardos PS, Dobson GL, Li J, et al. Evaluation of the MDR-MDCK cell line as a permeability screen for the blood-brain barrier. Int J Pharmaceut 288:349-359, 2005.

88. Doan KM, Humphreys JE, Webster LO, Wring SA, Shampine LJ, Serabjit-Singh CJ, et al. Passive permeability and P-glycoproteinmediated efflux differentiate central nervous system (CNS) and
non-CNS marketed drugs. J Pharmacol Exp Ther 303:1029-1037, 2002.

89. van de Waterbeemd H, Camenisch G, Folkers G, Chretien JR, Raevsky OA. Estimation of blood-brain barrier crossing of drugs using molecular size and shape, and H-bonding descriptors. J Drug Target 6:151-165, 1998

90. Clark DE. In silico prediction of blood-brain barrier permeation. Drug Discov Today 8:927-933, 2003.

91. Goodwin JT, Clark DE. In silico predictions of blood-brain barrier penetration: considerations to 'keep in mind.' J Pharmacol Exp Ther, in press.

92. Subramanian G, Kitchen DB. Computational models to predict blood-brain barrier permeation and CNS activity. J Comput Aided Mol Des 17:643-664, 2003.

93. Waterhouse RN. Determination of lipophilicity and its use as a predictor of blood-brain barrier penetration of molecular imaging agents. Mol Imaging Biol 5:376-389, 2003.

94. Fu XC, Song ZF, Fu CY, Liang WQ. A simple predictive model for blood-brain barrier penetration. Pharmazie 60:354-358, 2005.

95. Ecker GF, Noe CR. In silico prediction models for blood-brain barrier permeation. Curr Med Chem 11:1617-1628, 2004.

96. Strazielle N, Ghersi-Egea JF. Factors affecting delivery of antiviral drugs to the brain. Rev Med Virol 15:105-133, 2005.

97. Podlogar BL, Muegge I. "Holistic" in silico methods to estimate the systemic and CNS bioavailabilities of potential chemotherapeutic agents. Curr Top Med Chem 1:257-275, 2001.

98. Feng MR. Assessment of blood-brain barrier penetration: in silico, in vitro and in vivo. Curr Drug Metab 3:647-657, 2002. 